\title{
O GÊNERO IDENTITÁRIO NO AMBIENTE ESCOLAR: PRECONCEITOS ESTEREÓTIPOS
}

\author{
Ivone Maria BATTISTELA, SEED-PR
}

\begin{abstract}
RESUMO: Este trabalho tem por objetivo apresentar um estudo sobre a visão de gênero no ambiente escolar. Propõe mostrar como crianças e jovens veem a mulher e o homem por meio de atribuições adjetivas e como no espaço escolar reitera-se certos estereótipos em relação ao gênero feminino e masculino. O trabalho baseou-se na pesquisa qualitativa, na abordagem pósestruturalista. Concluiu-se que o preconceito de gênero está ainda muito presente na linguagem verbal e nas atitudes das pessoas.
\end{abstract}

PALAVRAS-CHAVE: gênero; identidade; escola.

ABSTRACT: This paper has the aim to present a study of gender in a public school setting. It aims to show the view of students have of male and female by ascribing adjectives to them; and how a stereotyped view of gender is reiterated in school settings. The study is based on qualitative analysis in a poststructuralist perspective. The result of the analysis shows that gender prejudice is still present in people's speech and attitude.

WORD KEY: gender; identity; school.

\section{INTRODUÇÃO}

A questão "gênero" vem sendo muito discutida nos últimos tempos. Pesquisas realizadas mostram que a visão tradicional de gênero continua sendo reproduzida no ambiente escolar pelas diferentes práticas sócio-interativas (PARAÍSO, 1998; LOPES, 2004; AUAD, 2006; BRAZ, 2006; GODOI, 2009). Instituições como a família, a escola e grupos de amigos podem ser vistas como comunidades onde reiteram-se certas visões e comportamentos estereotipados de gênero pelas práticas interativas entre seus membros e o mundo que os cerca, o qual é intermediado pela linguagem nas suas diferentes formas. A linguagem como mediadora concede às pessoas o poder de ação e de persuasão. É ela que nos dá a possibilidade de percebermos quem somos, como somos vistos e como devemos nos comportar, muitas vezes para sermos aceitos.

A visão tradicional de gênero, muitas vezes, passa despercebida, pois sendo construída culturalmente, é aceita sem haver um questionamento. Assim ela é reiterada. É só estarmos 
atentos e observarmos como em nossa volta a visão hierárquica e estereotipada ainda está presente no cotidiano da vida das pessoas, nas atitudes e nos papéis assumidos pelo homem ou pela mulher diante dos afazeres, bem como na linguagem que usamos para expressar nossa percepção de mundo.

A escola é um ambiente que propicia ao aluno construir e reconstruir-se nos papéis referentes ao gênero, pois é um ambiente adequado à reflexão e ao questionamento dos papéis tradicionalmente atribuídos a ambos os sexos desde os primeiros dias de vida, dos mitos e certos valores comportamentais edificados no curso de sua existência. Ela é um meio onde o aluno, ao interagir com seus colegas, professores e materiais didáticos, constrói, em parte, seu conhecimento, seus saberes, a visão de si e do mundo do qual faz parte. É também um lugar social e comunitário que exerce influência na construção da identidade e da identidade de gênero das crianças e jovens; um espaço onde aprendem como comportar-se e agir diante da sociedade.

Este estudo propõe mostrar a visão que meninos e meninas, crianças e adolescentes de uma escola do interior do Paraná têm em relação ao gênero feminino e masculino representados na mãe e no pai, na mulher e no homem; que visões têm de si enquanto seres identitários; e, se a escola é um espaço para a reiteração de certos estereótipos e como isso é feito. Inicialmente discute-se sobre linguagem, gênero e discurso. Em seguida, apresenta-se a metodologia, a análise e reflexão dos resultados da pesquisa.

\section{LINGUAGEM, GÊNERO E DISCURSO}

A linguagem pode ser vista como a principal contribuinte para a construção, reconstrução, ou reiteração de certas práticas e visões de como as pessoas devem ser e apresentar-se no ambiente no qual estão inseridas. Como parte da sociedade, e resultado de práticas sociais (HALLIDAY, 1978; FAIRCLOUGH, 2002), a linguagem é um meio que nos possibilita agir e refletir sobre a vida das pessoas e sobre o que fazem. O que tem sido socialmente produzido torna-se disponível às pessoas para que façam parte dessa produção através da prática social. Pois, é através dos atos e trocas de significados oriundos da interação entre indivíduos, linguagem e contexto que valores e conhecimentos são criados, transmitidos e estabelecidos. 
Um indivíduo aprende como comportar-se desde sua infância; aprende através de uma variedade de pequenos eventos do seu dia- a- dia, através de grupos sociais como a família e vizinhos. No grupo social em que participa, adota sua cultura, crenças e valores. Eckert (2003) identifica os grupos sociais como práticas comunitárias, nas quais os indivíduos, com interesses comuns, agem e interagem. Gradualmente, através dos diferentes modos de agir e interagir, adquirem seus valores e crenças. Desse modo, aprendem como pensar e como comportar-se de acordo com a norma do grupo do qual participam.

Nas diferentes práticas comunitárias (ECKERT, 2003), ou eventos nos quais participam, os indivíduos não só aprendem como comportar-se, como também representar seu papel identitário de gênero de acordo com o contexto o qual estão envolvidos (CAMERON, 2004). Num contínuo processo interativo e troca de experiências, constroem e reconstroem sua identidade de gênero.

Vendo a linguagem como um meio que manifesta a atitude e comportamento das pessoas em relação às situações e eventos que ocorrem ao seu redor, pode-se dizer que é através dela que os indivíduos manifestam sua identidade de gênero, uma vez que a linguagem contribui para que os indivíduos tenham a noção de si e dos outros como certos tipos identitários (CAMERON, 2000), por meio de representações simbólicas da sociedade (ECKERT, 2003) como olhar, modos de vestir-se, modos particulares de falar, e modos de comportar-se. O gênero como um "sistema de significados" (ECKERT, 2003,p.6) representado pela linguagem (JOHNSON,1997) dá aos indivíduos a concepção sobre a sua identidade feminina ou masculina. Nas comunidades em que participam aprendem a comportar-se de acordo com sua identidade.

Nesse sentido, o discurso pode ser identificado como modos de representar, entender e ser no mundo (GEE, 1999). Foucault (2002) vê como uma prática que forma sujeitos e objetos. No discurso que participam ou nas práticas comunitárias nas quais fazem parte ECKERT (2003), os indivíduos constroem-se e assumem-se ser representantes.

Instituições sociais como a família, a igreja e a escola têm seus próprios discursos constituídos em valores, atitudes e modos particulares de pensar, ver e ser no mundo. Cada um corresponde a posições diferentes (FAIRCLOUGH, 2002) e possui suas próprias regras. Cada pessoa não somente participa, como também traz para a sua vida muitos dos discursos 
disponíveis no mundo e no meio ao qual faz parte. Portanto, cada um tem suas particularidades, características e pensamentos construídos na cultura, nos valores e nas crenças.

FAIRCLOUGH (2002) menciona que o discurso é uma prática social que nasce das estruturas e processos sociais, que representa o mundo e que dá significado para tal mundo; menciona que a sociedade pode ser reproduzida ou transformada pela prática do discurso. Nesse sentido, identidades sociais, relações sociais, conhecimentos e crenças podem ser reproduzidos, modificados ou transformados.

Assim, pode-se afirmar que os discursos manifestam-se pela linguagem. Portanto, linguagem e discurso não podem ser concebidos separadamente, ambos estão integrados, e dependem um do outro para transmitir suas características e significados.

Na perspectiva pós-estruturalista, o discurso é visto como o principal meio através do qual um indivíduo constrói sua identidade, pois nessa perspectiva, o discurso e a prática são vistas como as bases para a construção da realidade. A realidade e a experiência são construídas através de atos e práticas da linguagem (CAMERON, 2001). Os indivíduos estão sempre sujeitos a forças culturais ou práticas discursivas, e é especialmente nas práticas discursivas da linguagem e do discurso que identidades são construídas num processo constante e contínuo.

\section{PROCEDIMENTOS METODOLÓGICOS}

A fim de investigar a percepção de gênero desenvolvida por alunos da escola pública desenvolvi uma pesquisa no ano de 2009 em duas turmas de alunos em uma pequena escola Estadual localizada no interior do município de Cascavel; em uma turma de $5^{\mathrm{a}}$. série do Ensino Fundamental composta por 16 alunos, e em uma turma de $2^{\circ}$. ano do Ensino Médio composta por 12 alunos. A coleta de dados para a análise realizou-se através de um questionário para os alunos da $5^{\mathrm{a}}$. série, o que consistia em atribuir quatro adjetivos para caracterizar a mãe, quatro para caracterizar o pai e quatro adjetivos para caracterizar a eles próprios. Para os alunos do $2^{\circ}$. ano, a coleta de dados obteve-se através de um questionário e um debate na sala de aula. $\mathrm{O}$ questionário consistia em atribuir quatro características para a mulher e quatro para o homem. Para a realização do debate foram elaboradas as seguintes perguntas: Você acha que a mulher 
hoje é discriminada? O menino é tratado diferente da menina? Além dessas questões, outras foram elaboradas espontaneamente no andamento da discussão.

Este estudo não objetivou analisar dados quantitativos, mas sim os significados transmitidos através da frequência, diferença e omissão de dados. Como a análise envolve significados transmitidos pelas práticas discursivas da linguagem, optou-se por uma metodologia mais próxima a este modo de ver que é por uma análise qualitativa dos dados na visão pósestruturalista. Nessa abordagem, discurso e prática são vistos como as bases para a construção da realidade. Ela dá ênfase ao sujeito, a construção da realidade, aos significados e às experiências (USHER e EDUARDS, 1996). A realidade e a experiência são vistas como situações constituídas pelos atos e práticas da linguagem (CAMERON, 2002); os indivíduos são sempre sujeitos das forças culturais ou das práticas discursivas. É por meio dela que identidades são construídas continuamente (BAXTER, 2003).

\section{ANÁLISE E REFLEXÃO SOBRE OS RESULTADOS}

\begin{tabular}{|l|l|l|l|l|l|}
\hline Mãe & bonita (7) & legal (6) & carinhosa (6) & bondosa (5) & Inteligente (5) \\
\hline Pai & legal (8) & Trabalhador (7) & Carinhoso (5) & bondoso (5) & Inteligente (3) \\
\hline
\end{tabular}

quadro $1-5^{\mathrm{a}}$. série

\begin{tabular}{|l|l|l|l|l|l|}
\hline Meninas & bonita (5) & legal (5) & Inteligente (3) & chata (2) & metida (2) \\
\hline Meninos & bonito (4) & feliz (3) & outros & & \\
\hline
\end{tabular}

quadro $2-5^{\mathrm{a}}$. série

\begin{tabular}{|l|l|l|l|l|l|}
\hline Mulher & bonita (6) & delicada (4) & Inteligente (3) & $\begin{array}{l}\text { vaidosa e fiel } \\
(3)\end{array}$ & trabalhadora (2) \\
\hline Homem & trabalhador (6) & bonito 6) & forte (3) & fiel (2) & inteligente (2) \\
\hline
\end{tabular}

quadro $3-2^{\circ}$. ano

Através dos quadros acima, pode-se observar que há semelhanças e diferenças no número de atribuições de adjetivos para caracterizar a mulher e o homem. Tanto a mulher quanto o homem estão caracterizados pelos adjetivos "legais", "bondosos", "carinhosos" e "inteligentes" em números semelhantes pelos alunos da $5^{\mathrm{a}}$. série. A diferença desse quadro se faz pela palavra bonita - adjetivo atribuído à mãe, e pela palavra "trabalhador" - adjetivo atribuído ao pai. 
Observa-se que houve um grande número de alunos que usou o adjetivo "bonita" para identificar a mãe, e o adjetivo "trabalhador" para identificar o pai. Interessante observar que nenhum dos alunos identificou o pai pelo adjetivo "bonito", como também nenhum identificou a mãe pelo adjetivo "trabalhadora".

Já no quadro 2, um grande número de meninos e meninas usa o adjetivo "bonito(a)" como uma das palavras para descreverem-se. Contrário ao que é apresentado no quadro 1, um número favorável de alunos da turma do $2^{\circ}$. ano usou o adjetivo "bonito(a)" para caracterizar ambos os gêneros; e um número maior de atribuições do adjetivo "trabalhador" é dado ao homem. No quadro 3, também pode-se observar que os adjetivos "delicada" e "vaidosa" foram atribuídos à mulher e "forte" ao homem.

Por meio desses dados, pode ser evidenciada a visão ainda preconceituosa que se construiu ao longo da história; uma visão de que o homem tem sido o provedor, o ser que trabalha e que mantém o sustento da família. Nisso, observa-se um modo de perceber que é desprovido de uma reflexão. A linguagem, vista como uma forma representacional que emite significados, vem, nesse sentido, mostrar essa visão mítica presente na consciência coletiva das pessoas.

Uma visão estereotipada pela atribuição de valores qualitativos evidenciou-se também na discussão com a turma do $2^{\circ}$. ano. A turma, durante uma discussão, fez comentários sobre uma aluna atleta e homossexual que participava de um evento esportivo. Uma das alunas relata que "ela é muito forte, mas linda". Percebe-se, nessa afirmação, que os adjetivos atribuídos à atleta tem uma força conotativa que remete ao masculino e ao feminino. Observa-se que o adjetivo "forte" faz referência ao corpo físico da atleta, a um corpo que conota masculinidade, e o adjetivo "linda" faz referência à beleza com sua conotação feminina. Nisso, percebe-se uma descrição estereotipada em relação ao gênero feminino e masculino pela atribuição dos adjetivos. Interessante foi observar que, o que a aluna afirmou sobre a atleta, outras colegas do grupo também acabaram reafirmando e repetindo a expressão. Desse modo percebe-se como a prática social da fala reproduz o discurso.

Pela linguagem pode-se observar como os sujeitos são posicionados diante dos discursos de gênero. Isso percebe-se quando os sujeitos utilizam certas palavras ou expressões condenativas diante das situações ou diante daquilo que ouvem e veem, ou melhor, diante dos 
discursos que não condizem com a visão ou com a prática cultural das pessoas. Um exemplo disso evidencia-se através do relato de uma aluna do $2^{\circ}$.ano quando discutia-se sobre a a existência do preconceito de gênero, pois a aluna trouxe para a discussão uma situação vivenciada, na qual um colega de escola acusou-a de "seu machão" por ter uma voz "mais grossa”. Observa-se que tal voz, na visão desse colega, não seria uma voz condizente com as práticas associadas à feminilidade, e sim, ao discurso masculino com atributos associados à masculinidade. Percebe-se aqui que esse colega assume uma atitude condenativa ao que não é normal ao discurso binário de gênero, demonstrando, assim, uma atitude e uma visão estereotipadas e discriminatórias em relação a aspectos que não condizem ao seu modo de ver e pensar.

O discurso hegemônico da masculinidade, muitas vezes, pode ser um problema para os meninos e meninas que não compartilham da visão de que todo o menino deve ser heterossexual, pois podem ser marginalizados ou discriminados. Isso observa-se em um outro relato posto por um dos alunos sobre uma situação presenciada em um evento promovido pelo Programa Viva Escola, Governo do Paraná, Fera Com Ciência ocorrido há um ano. Ele relata que em um grupo de alunos de uma das escolas participantes havia um menino com tendência homossexual, e comenta que, "a turma não quiz fazer trabalhos com esse menino". Diante desse fato, percebe-se também que o grupo de alunos que rejeitou a presença do colega, está envolto por valores e concepções que não admitem padrões de comportamentos que não condizem com a visão binária de gênero. Essa atitude tomada em relação ao colega pode também ser uma representação afirmativa dos membros do grupo de que pertencem ao discurso heterossexual. Esses exemplos remetem a uma mesma situação observada por Lopes (2004) em que há um posicionamento representativo dos indivíduos diante de certos modos de ser e de agir que não são compatibilizados pelo grupo a que pertencem.

Semelhantes a esses exemplos somam-se outros, como em Paraíso (1998), Auad, (2006), Braz (2006) e Godoi (2009), pelos quais percebe-se como as pessoas veem o gênero feminino e masculino de forma distinta; neles as pessoas posicionam-se e são posicionadas diante dos atos e atitudes que veem, ou melhor, diante das determinações de cada discurso (FOUCAULT, 2002).

Uma das respostas para a pergunta, que questionava se havia tratamento diferenciado entre meninos e meninas, uma das alunas respondeu que "homens são mais pulso firme, por isso 
há mais homens no governo". Na resposta, a aluna justifica o motivo por haver mais homens assumindo cargos de governo, por serem diferentes das mulheres. Pela sua afirmação e justificativa percebe-se, aqui também, a presença de uma visão hierárquica e tradicional. Nesse caso, a aluna vê tal cargo assumido pelo homem devido a sua capacidade, a qual justifica-se por uma qualidade que, percebe-se, está no imaginário das pessoas, pois à característica forte atribuída ao homem, soma-se a ideia de que ele é forte e competente, e que são atributos que lhe dão capacidades para administração. Implícito a resposta, está a ideia de que a mulher é frágil, não tem tanta competência quanto ao homem para assumir a tal cargo. Observa-se que o valor atribuído ao homem retoma a visão binária e comparativa de superioridade e inferioridade, e nesse caso, o homem é visto como superior. Essa noção também está ilustrada na pesquisa realizada por PARAÍSO (1998), pois, o homem, visto como superior, é "inteligente" e por isso deve almejar por altos cargos que lhe deem "mais dinheiro".

\section{CONCLUSÃO}

Este estudo teve por objetivo analisar como crianças e adolescentes estudantes veem a questão "gênero" no ambiente escolar; que atribuições utilizam para identificar a mulher e o homem, e a si mesmos; e se a escola é um espaço para a reiteração de certos estereótipos e como isso é feito.

Através da pesquisa observou-se que uma visão tradicional de gênero ainda persiste no imaginário dos alunos. Homens e mulheres são ainda vistos de forma dicotômicas, com valores hierárquicos e atribuições diferenciadas. Constatou-se que os indivíduos, diante dos discursos de gênero, assumem atitudes de aceitação e oposição como forma para identificarem-se ao discurso do qual fazem parte. Diante disso, atitudes, modos de ser e agir que não estão de acordo com a visão tradicional do discurso de gênero, são, muitas vezes contestados por meio de atitudes opostas e condenativas. Desse modo, observa-se que os indivíduos, ao mesmo tempo em que assumem o papel de sujeitos, também exercem o papel de objetos do discurso do qual fazem parte. Também observou-se que a discriminação apresenta-se de forma evidente e explícita às pessoas que não apresentam atitudes de acordo com as normas tradicionais do discurso de gênero ou que não compartilham com o discurso hegemônico da feminilidade e masculinidade. 
Essas observações são algumas, entre outras, em que percebe-se como as relações que envolvem a questão "gênero" estão muito presentes na vida das pessoas. O ambiente escolar é um meio onde elas manifestam seus modos de agir e pensar diante das situações e acontecimentos vivenciados ou presenciados. Assim, pode-se observar que, embora haja a contestação ao preconceito de gênero, ele ainda está muito presente nas atitudes, comentários e exemplificações expressos pelas pessoas. Dessa forma e de outras, que muitas vezes se apresentam de modo sutil, o preconceito ao gênero continua sendo reproduzido. A visão hierárquica e estereotipada dos papéis assumidos pela mulher e pelo homem continua a reproduzir-se quando não se discute, nem se leva em consideração que a construção da identidade feminina e masculina é uma construção cultural e social capaz de mudanças e transformações. Quando não se questiona contribui-se para a reiteração de atitudes preconceituosas com relação ao gênero. A transformação só ocorre através de uma reflexão sobre as atitudes, modos de ser e comportar-se que priorizam classificam e discriminam.

\section{REFERÊNCIAS}

AUAD, Daniela. Relação de gênero nas práticas escolares e a construção de um projeto coeducação, 2006. Disponível em: http://www.anped.org.br/reunioes/27/ge23/t233.pdf. Acesso: 05 nov. 2009.

BAXTER, Judith. Positioning gender in discourse: feminist methodology. London, Palgrave Macmillan, 2003.

BRAZ, Irles Maria Araújo e ROMERO, Eliane. Relações de gênero entre crianças de $4^{a}$. série : uma construção permeando as atividades em sala de aula e na educação física escolar, 2006. Disponível em:

http://www.fazendogenero7.ufsc.br/artigos/B/Braz Romero 07_B.pdf. Acesso: 31 out. 2009.

CAMERON, Deborah. Working with spoken discourse. London: Sage, 2002.

Performing gender identity: young Men's talk and construction of heterosexual masculinities. In: COATES, Jennifer. Women, men and language. Great Britain: Person Education, 2004. p. 271-284

FAIRCLOUGH, Norman. Discourse and social change. UK: Blackwell, 2002.

FOUCAULT, Michael. The archaelogy of knowledge. London: Routledge, 2002. 
GEE, James Paul. Local linguistics and literacies: ideology in discourses. London: The Falmer Press, 1999.

GODOI, M. R. Governo dos corpos, gênero e sexualidade: reflexões sobre situações do cotidiano nas escolas, 2009. Disponível em http://www.efdeportes.com/efd134/governo-doscorpos-genero-e-sexualidade.htm. Acesso: 05 nov. 2009.

GRAY, David E. Doing research in the real world. London: Sage, 2004.

JOHNSON, Sally. Theorizing Language and Masculinity: A feminist perspective. In Johnson, Sally at al. Language and Masculinity. Oxford: Blackwell, 1997. p 8-26

HALLIDAY, Michael Alexander Kirkwood. Language and social semiotic: the social interpretation of language and meaning. London: Eduard Arnold, 1978.

MINELLA, Luzinete Simões. Papéis sexuais e hierarquias de gênero na história social sobre a infância no Brasil, 2006. Disponível em: http://www.scielo.br/pdf/cpa/n26/30395.pdf. Acesso: 5 de nov. 2009.

MOITA LOPES, Luis Paulo de. Discurso sobre gays em uma sala de aula no Rio de Janeiro: é possível queer nos contextos de letramento escolar?, VIII CONGRESSO LUSO-AFROBRASILEIRO DE CIÊNCIAS SOCIAIS, setembro de 2004, Coimbra. http://www.ces.uc.pt/lab2004/inscricao/pdfs/painel3/LuizLopes.pdf. Acesso: 05 nov. 2009.

PARAÍSO, Marlucy Alves. (1998) Currículo e identidades: a produção de gênero, sexualidade e etnia na formação da professora.Disponível em: http://cappf.org.br/tikiindex.php?page=G\%C3\%AAnero\%3A+Para\%C3\%ADso. Acesso: 05 de nov. 2009.

USHER, Robin and Eduards, Richard. Postmodernism and education. London: Routledge, 1996. 